\title{
Japan promises more money for university research
}

Tokyo. Japan's Ministry of Education, Science and Culture (MESC) has asked for a 14 per cent increase in the money it has to spend on competitive research grants for university researchers in its budget request for the fiscal year starting on 1 April 1994.

If granted - as seems likely - the request will bring some welcome relief to Japan's cash-starved university researchers.

It also puts the ministry on target for achieving the goal set last year by its principal advisory council of almost doubling its research grants budget to $¥ 100$ billion (about US $\$ 1$ billion) over the next few years (see Nature 358, 359; 1992).

The budget request, for a total of $¥ 83.9$ billion, was submitted earlier this month to the Ministry of Finance. It is likely to be trimmed back by the ministry before being given final approval by the cabinet at the end of December. But only minor changes are expected

A substantial increase has been requested in the plan to upgrade the university computer networks which will plugged into a new national "backbone" network. The local networks form part of a strategy that will result in a dramatic improvement in computer communications both within and between universities and national research institutes over the next year (see Nature 365, 7; 1993).

Funding for the overall project is also being sought by the Science and Technology Agency (STA) and the Ministry of International Trade and Industry. The backbone network, called SINET, runs from Japan's northern island of Hokkaido to the

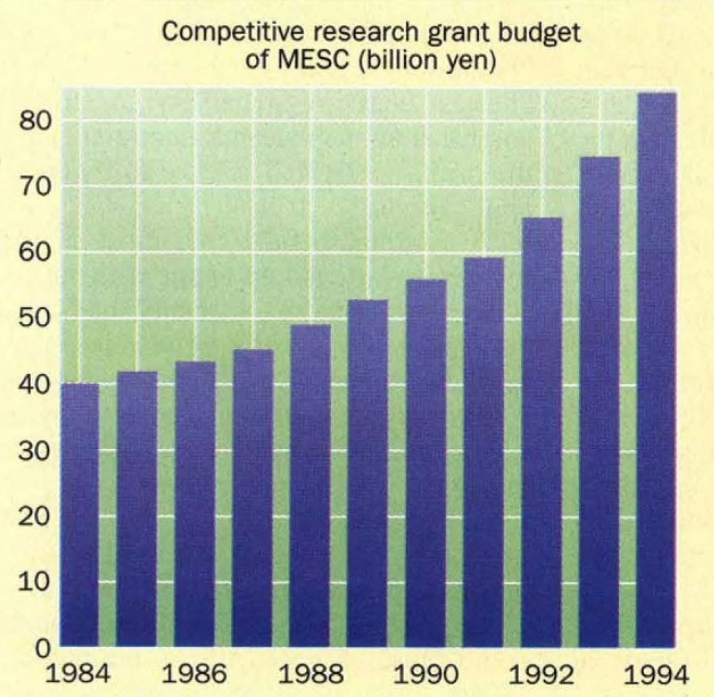

Research grants for university scientists are on course to double within a few years. southern island of Kyushu through the main island of Honshu.

Just over $¥ 30$ billion — a 13.6 per cent increase - is being requested by the education ministry to upgrade the computer networks linking the universities. The new funding will increase the capacity of the network by a factor of more than ten, from 512 kilobits per second to 6 megabits per second. Branch lines will be increased from the relatively slow speed of 9.6 kilobits per second to 512 kilobits per second.

The whole network will be linked to the 6-megabit inter-ministry national backbone network planned by the STA, and the university network will also have two 2-megabit links to computer networks overseas.

The budget proposals also include MESC's first funding for its next major project in high-energy physics. The ministry is asking for $¥ 2$ billion to begin construction of the B-meson factory to be built at the National Laboratory of High Energy Physics (KEK) in Tsukuba.

Japan's high-energy physicists have agreed that the B-meson factory should be their next major project. There had been fears that the Ministry of Finance would not be prepared to provide the financing if Japan is also required to contribute to the construction of the US Superconducting Super Collider (SSC).

But with the SSC struggling to survive in the US Congress, pressure on Japan to contribute has eased, allowing for the plans to build the B-meson factory to move ahead. The factory, which will be built within the ring of the existing TRISTAN electronpositron collider at KEK, should be operational within five years of the start of construction next year.

Japanese university researchers have been complaining for years about the small size of the ministry's budget for research grants. Yasutomi Nishizuka, for example, a leading molecular biologist at Kobe University, points out that the entire grant budget - which stands at $¥ 73.6$ billion this year - is about the same as the budget of Johns Hopkins University in the United States.

The government budget for such grants is now rising rapidly. In contrast, there has been a dramatic slowing down in the expansion of funding from private industry to support
MESC'S BUDGET REQUEST FOR SCIENCE IN 1994

\begin{tabular}{|lcc|}
\hline & $\begin{array}{c}\text { billion } \\
¥\end{array}$ & $\begin{array}{c}\% \text { change } \\
\text { from 1993 }\end{array}$ \\
\hline Grants-in-aid of research & 83.9 & +14.0 \\
Government/industry research & 15.3 & +0.5 \\
Donations from industry & 52.1 & +4.0 \\
Computer networks & 30.3 & +13.6 \\
Nuclear fusion & 13.2 & +2.9 \\
Accelerator physics & 13.0 & +6.9 \\
$\quad$ (TRISTAN and B factory) & & \\
Space science & 21.5 & +4.3 \\
Astronomy (Hawaiian telescope) & 4.8 & +19.3 \\
Earthquake and volcanic & 2.7 & +11.3 \\
$\quad$ eruption prediction & & \\
Antarctic research & 3.8 & +8.6 \\
Japan Society for Promotion & 11.0 & +22.2 \\
$\quad$ of Science (JSPS) & \multicolumn{2}{l}{} \\
\end{tabular}

university researchers.

By the end of the 1980s, following a period of rapid economic growth, the total of such research funds almost came to match those provided by the government. But as a result of the recession that has gripped Japan over the past two years, the ministry predicts that grants from industry will rise by only four per cent next year.

David Swinbanks

\section{Senate seeks to cut NASA's search for "Green Martians"}

Washington. The US Senate appears to have delivered a fatal blow to a bid by the National Aeronautics and Space Administration (NASA) to mount a search for life in outer space.

NASA had tried to overcome congressional scepticism to its proposal by renaming its planned Search for Extraterrestrial Intelligence (SETI) programme as the High Resolution Microwave Study. John Rummel, chief scientist of the 10-year \$104million programme, insists that it would involve good science, and points out that it has received repeated support from independent panels of the National Academy of Sciences and elsewhere (see Nature 364 . 750; 1993).

But in moving an amendment to kill the coming year's funding for the project, Senator Richard Bryan (Democrat, Nevada), accused NASA of defying an earlier congressional instruction to cut SETI. The Senate backed the amendment by 77 to 23 .

In theory, SETI could still be saved when a joint committee of the House of Representatives and Senate meets this week to finalize the budget. But the margin of the Senate vote makes this unlikely. "The Green Martian chase may finally come to an end," predicts Bryan. "This is a low priority and should be put on the shelf."

Colin Macilwain 